Article

\title{
Spectral Properties of Substituted Coumarins in Solution and Polymer Matrices
}

\author{
Jana Donovalová ${ }^{1, *}$, Marek Cigáň ${ }^{1}$, Henrieta Stankovičová ${ }^{1}$, Jan Gašpar ${ }^{1}$, Martin Danko ${ }^{2}$, \\ Anton Gáplovský ${ }^{1}$ and Pavol Hrdlovič ${ }^{1,2}$
}

1 Faculty of Natural Sciences, Institute of Chemistry, Comenius University, Mlynská dolina CH-2, SK-842 15 Bratislava, Slovak Republic; E-Mails: cigan@fns.uniba.sk (M.C.); stankovh@fns.uniba.sk (H.S.); gaspar@fns.uniba.sk (J.G.); gaplovsky@fns.uniba.sk (A.G.); upolhrdl@savba.sk (P.H.)

2 Polymer Institute, Slovak Academy of Sciences, 84541 Bratislava, Dúbravská cesta 9, Slovak Republic; E-Mail: upoldan@savba.sk

* Author to whom correspondence should be addressed; E-Mail: donovalova@fns.uniba.sk; Tel.: +421-2-6029-6306; Fax: +421-2-6029-6337.

Received: 23 January 2012; in revised form: 7 March 2012 / Accepted: 8 March 2012 /

Published: 14 March 2012

\begin{abstract}
The absorption and fluorescence spectra of substituted coumarins (2-oxo- $2 \mathrm{H}$ chromenes) were investigated in solvents and in polymer matrices. The substitutions involved were: (1) by groups with varying electron donating ability such as $\mathrm{CH}_{3}, \mathrm{OCH}_{3}$ and $\mathrm{N}\left(\mathrm{CH}_{3}\right)_{2}$, mainly, but not exclusively, in positions 7 and (2), by either $\mathrm{CHO}$ or 4- $\mathrm{PhNHCONHN}=\mathrm{CH}$ - in position 3. While the spectra of non-substituted coumarin-3carbaldehyde has absorptions at approximately 305 and $350 \mathrm{~nm}$, substitution at position 7 leads to remarkable changes in the shape of the absorption spectrum and shifts the absorption to a longer wavelength. Similarly, the replacement of the formyl group with a semicarbazide group substantially influences the shape of the absorption spectrum, and coumarins which have only $\mathrm{N}\left(\mathrm{CH}_{3}\right)_{2}$ in position 7 experience small changes. These changes are associated with the increasing intramolecular charge transfer (ICT) character and increasing conjugation length of the chromophoric system, respectively, in the studied molecules. The fluorescence is almost negligible for derivatives which have $\mathrm{H}$ in this position. With increasing electron donating ability, and the possibility of a positive mesomeric $(+\mathrm{M})$ effect of the substituent in position 7 of the coumarin moiety, the fluorescence increases, and this increase is most intense when $\mathrm{N}\left(\mathrm{CH}_{3}\right)_{2}$ substitutes in this position, for both 3-substituted derivatives. Spectral measurements of the studied
\end{abstract}


coumarins in polymer matrices revealed that the absorption and fluorescence maxima lay within the maxima for solvents, and that coumarins yield more intense fluorescence in polymer matrices than when they are in solution. The quantum yield of derivatives which have a dimethylamino group in position 7 in polymer matrices approaches 1 , and the fluorescence lifetime is within the range of 0.5-4 ns. The high quantum yield of 7-dimethylamino derivatives qualifies them as laser dyes which have $k_{\mathrm{F}}$ higher than $k_{\mathrm{nr}}$ in the given medium. This is caused by stiffening of the coumarin structure in polar polymer matrices, such as PMMA and PVC, due to higher micro-viscosity than in solution and intermolecular dipole-dipole interaction between chromophore (dopant) and matrix.

Keywords: fluorescence; substituted coumarins; solvent effect; polymer matrices

\section{Introduction}

Although the non-substituted parent coumarin (2-oxo-2H-chromene) exhibits zero or very weak fluorescence, properly substituted derivatives yield intense fluorescence and these are widely used in different branches of chemistry, biology, medicine and physics [1,2]. These derivatives are an important part of fluorescence probes, sensors and switches, as reviewed by Prasanna de Silva $[3,4]$. These have also been recently used for enantioselective sensing [5].

The influence of the environment (proximity) of substituted coumarins on photo-physics has been extensively studied with steady state and time resolved spectroscopy [5-21]. Since the fluorescence of coumarin derivatives is dependent on their environment, they are an important structural unit for probes widely used in monitoring the polarity and micro-viscosity of the environment in various simple, mixed or ionic solvents [1-21].

The strong solvent dependence of various coumarins has been exploited in the characterization of micelles [22-25]. They respond spectrally to other cavities, including inclusion complexes [26,27], within the cavities of porous materials and on their surface [28,29]. They are used in the characterization of materials prepared by sol-gel processes [30-32], and of nano-particles such as silica and silver [33,34].

The fluorescence of coumarins is widely used as a research tool in polymer science [35,36]. Moreover, they are used as photo-initiators [37], for incorporation into polymer chains by co-polymerization [38], in the estimation of polymer solvent effects [39-41], for various structural characterization $[42,43]$, in the monitoring of the releasing properties of poly(methylmethacrylate) nanospheres [44] and for polymeric fluorescent solar collectors [45]. The influence of the polymer matrix on the decay of fluorescence of dialkylamino-substituted coumarins [46] and on the properties of photo-responsive hyperbranched polyesters [47] has been studied systematically. Coumarins may also serve as model compounds for lignin [48] and the characterization of cellulose surface polarity [49].

The quenching of 7-amino substituted coumarins by diphenyl and triphenylamine derivatives has been investigated by both steady state and time resolved spectroscopy [50,51]. Therein, it was concluded that electron transfer in this process fits within the framework of the Marcus electron transfer theory. 
Coumarins have been used as structural units in fluorescence probes based on intramolecular quenching, and as reporters of radical reactions within solutions and thin polymer films [52-54]. The extent of intramolecular quenching depends on the coumarin structure, and for simple coumarin this was established to be in the range of $2-5$ in solution and up to 20 in polymer matrices [54].

Together with other chromophores, substituted coumarins are used as molecular rotors and fluorescence probes in biological studies [55].

Optical properties of the laser dye coumarin 500 were investigated after exposure to atmospheric coronal discharge, in order to imitate the degradation occurring during their application as a laser or textile dye. When this discharge exposure was found to result in extensive degradation [56], a new molecular design for coumarin fluorescence dyes was created. This was achieved by the introduction of an arylsulfonated group, and this improved its application in the textile industry [57].

Improved performance of probes and sensors based on coumarin chromophores was achieved by introducing an additional structural unit like a rigid crown to improve ion selectivity [58]. The exploitation of energy transfer was effected by introducing an additional chromophore, such as phthalimide [59] or 1,8-naphthylimide [60,61].

Those coumarins substituted by dialkylamino and/or amino goups are widely studied because of their ability to yield intense fluorescence or lase in the blue-green region. Their photo-physical properties are modified by electron withdrawing substituents, such as $\mathrm{CHO}$ or $-\mathrm{CH}=\mathrm{NNHCONHPh}$ [62] in position 3. This study reveals that the 3 -carbaldehyde exhibits a strong solvent effect in polar solvents due to the formation of a non-fluorescent twisted intramolecular charge transfer (TICT) state, while a locally excited intramolecular charge transfer (LE/ICT) state prevails when $-\mathrm{CH}=\mathrm{NNHCONHPh}$ substitutes in position 3.

In this study, eight coumarin derivatives [2-oxo-2H-chromene-3-carbaldehyde (1), (E)-1-[(2-oxo2H-chromen-3-yl)methylidene]-4-phenylsemicarbazide (2), 7-(dimethylamino)-2-oxo-2H-chromene-3carbaldehyde, (3), (E)-1-\{[(7-dimethylamino)-2-oxo-2H-chromen-3-yl]methylidene $\}$-4-phenylsemicarbazide (4), 7-methyl-2-oxo-2H-chromene-3-carbaldehyde (5), (E)-1-[(7-methyl-2-oxo-2Hchromen-3-yl)methylidene]-4-phenylsemicarbazide (6), 7-methoxy-2-oxo-2H chromene-3-carbaldehyde (7) and (E)-1-[(7-methoxy-2-oxo-2H-chromen-3-yl)methylidene]-4-phenylsemicarbazide 8 (Figure 1)], substituted in position 3 with an electron withdrawing substituent and with substituents of varying electron donating ability in position 7 were investigated spectrally in solution and in a polymer matrix.

Figure 1. Molecular structure of the studied molecules.<smiles>[R]c1ccc2cc(C=O)c(=O)oc2c1</smiles><smiles>[R]c1ccc2cc(/C=N/NC(=O)Nc3ccccc3)c(=O)oc2c1</smiles>

$$
\begin{aligned}
& \mathrm{R}=\mathrm{H} \\
& \mathrm{R}=\mathrm{N}\left(\mathrm{CH}_{3}\right)_{2} \\
& \mathrm{R}=\mathrm{CH}_{3} \\
& \mathrm{R}=\mathrm{OCH}_{3}
\end{aligned}
$$


Two types of substituents in position 3, namely $\mathrm{CHO}$ and $\mathrm{PhNHCONHN}=\mathrm{CH}$, were compared regarding the ability to modify their spectral properties by binding various other units through hydrogen bonding. The steady state and time-resolved fluorescence measurements were performed in aerated solutions. All measurements on polymer films were performed in the air.

\section{Results and Discussion}

\subsection{Absorption Spectra}

The aim of the spectral study of the studied coumarins with electron withdrawing substituent like $\mathrm{CHO}$ or $\mathrm{CH}=\mathrm{N}-\mathrm{NHCONHPh}$ in position 3 and electron donating substituents with increasing electron donating power in position 7 (leading to formation of a push-pull system on coumarin structural unit) was to gain some insight into their photo-physics. The absorption spectra of the studied derivatives are quite similar in solution (Figure 2A) and in the polymer matrices (Figure 2B). The relevant absorption data established in the different media for derivatives 1-8 are summarized in Tables $1-3$.

Figure 2. (A) Absorption spectra of coumarins 1-8 in chloroform at $10^{-5} \mathrm{~mol} \cdot \mathrm{dm}^{-3}$. (B) Absorption spectra of coumarins 1-8 in PMMA at $0.002 \mathrm{~mol} \cdot \mathrm{kg}^{-1}$.
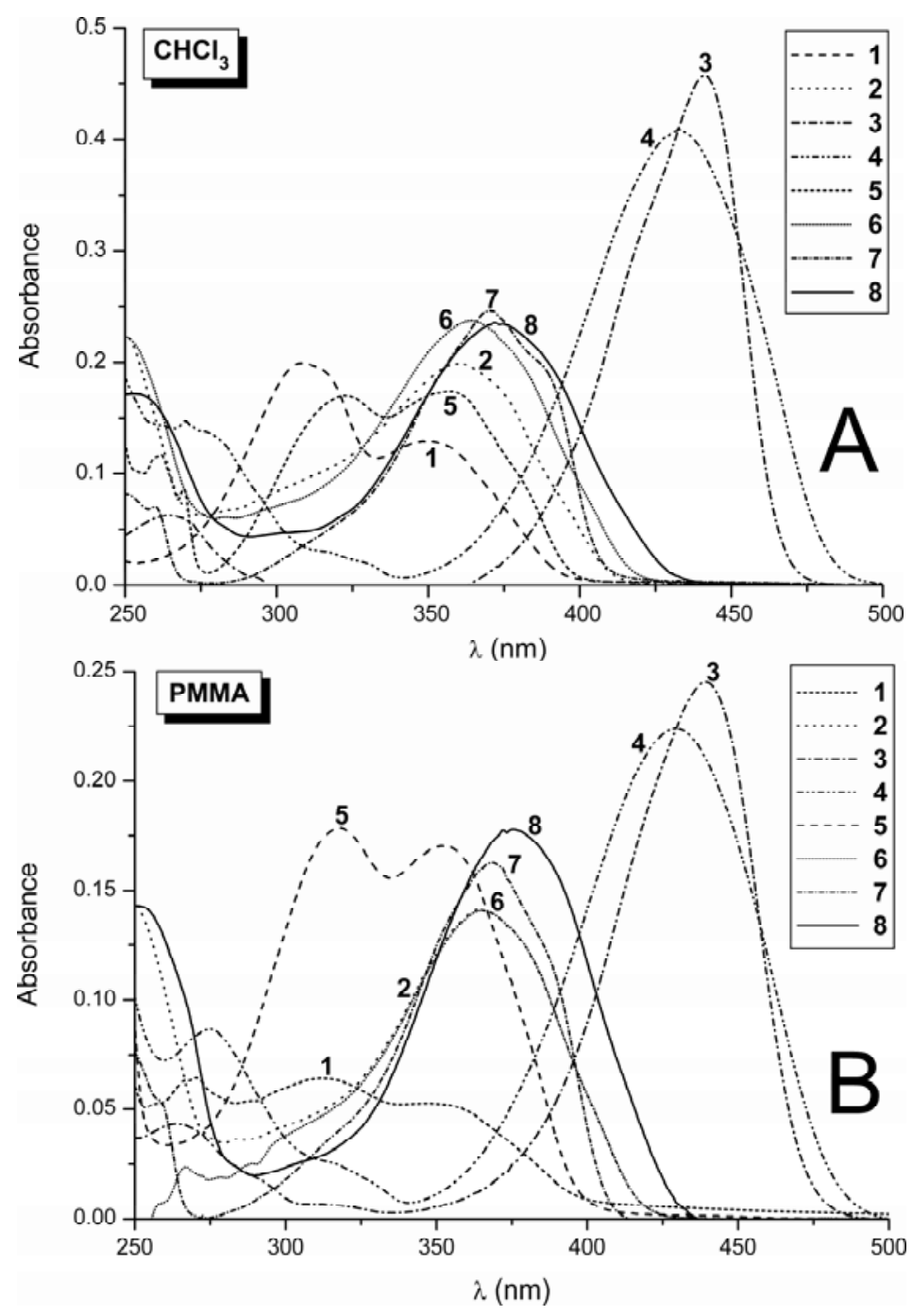
Table 1. Spectral data on UV absorption spectra of 1, 2, 5, 6 and 7.

\begin{tabular}{|c|c|c|c|c|c|}
\hline $\begin{array}{l}\text { Comp./ } \\
\text { Medium }\end{array}$ & $\begin{array}{c}1 \\
\lambda_{\mathrm{A}} / \log \varepsilon \\
(\mathrm{nm})\end{array}$ & $\begin{array}{c}2 \\
\lambda_{\mathrm{A}} / \log \varepsilon \\
(\mathrm{nm})\end{array}$ & $\begin{array}{c}5 \\
\lambda_{\mathrm{A}} / \log \varepsilon \\
(\mathbf{n m})\end{array}$ & $\begin{array}{c}6 \\
\lambda_{\mathrm{A}} / \log \varepsilon \\
(\mathrm{nm})\end{array}$ & $\begin{array}{c}7 \\
\lambda_{\mathrm{A}} / \log \varepsilon \\
(\mathrm{nm})\end{array}$ \\
\hline $\mathrm{MeOH}$ & $278 / 3.78 *$ & & $287 / 4.37 *$ & & \\
\hline $\mathrm{MeOH}$ & $310 / 3.56$ * & & $315 / 4.32 *$ & & \\
\hline $\mathrm{MeOH}$ & $354 / 3.10 *$ & $359 / 4.30$ & $360 / 4.03 *$ & $361 / 4.41$ & $361 / 3.96 *$ \\
\hline $\mathrm{CHCl}_{3}$ & $307 / 4.30$ & & $321 / 4.27$ & & \\
\hline $\mathrm{CHCl}_{3}$ & $348 / 4.12$ & $360 / 4.30$ & $356 / 4.24$ & $364 / 4.37$ & $370 / 4.39$ \\
\hline PMMA & $306 / 3.90$ & & $312 / 4.31$ & & \\
\hline PMMA & $351 / 3.72$ & $361 / 4.15$ & $347 / 4.23$ & $364 / 4.15$ & $368 / 4.20$ \\
\hline PVC & $311 / 3.85$ & & $321 / 4.12$ & & \\
\hline PVC & $357 / 3.67$ & $364 / 4.24$ & $357 / 4.08$ & $368 / 4.26$ & $372 / 4.32$ \\
\hline PS & $314 / 3.85$ & & $323 / 4.06$ & & \\
\hline PS & $351 / 3.74$ & $365 / 4.11$ & $357 / 4.07$ & $365 / 4.21$ & $372 / 4.22$ \\
\hline
\end{tabular}

The structure of compounds is given in Scheme $1 ; \lambda_{\mathrm{A}}$ : maximum of absorption, $\log \varepsilon: \log$ of decadic extinction coefficient; *: distorted value due to the formation of acetal.

Table 2. Spectral properties of disubstituted derivatives of coumarin 3,4 and 8 .

\begin{tabular}{ccccccccc}
\hline $\begin{array}{c}\text { Comp./ } \\
\text { Medium }\end{array}$ & $\begin{array}{c}\lambda_{\mathbf{A}} / \mathbf{l o g} \boldsymbol{\varepsilon} \\
(\mathbf{n m})\end{array}$ & $\begin{array}{c}\Delta \boldsymbol{v}_{\mathbf{1} / \mathbf{2}} \\
\left(\mathbf{c m}^{-\mathbf{1}}\right)\end{array}$ & $\begin{array}{c}\lambda_{\mathbf{F}} \\
(\mathbf{n m})\end{array}$ & $\begin{array}{c}\boldsymbol{\nu}_{\mathbf{A}}-\boldsymbol{\nu}_{\mathbf{F}} \\
\left(\mathbf{c m}^{-\mathbf{1}}\right)\end{array}$ & $\boldsymbol{\Phi}_{\mathbf{F}}$ & $\begin{array}{c}\boldsymbol{\tau} \\
(\mathbf{n s})\end{array}$ & $\begin{array}{c}\boldsymbol{k}_{\mathbf{F}} \\
\left(\mathbf{1 0}^{\mathbf{9}} \mathbf{s}^{-\mathbf{1}}\right)\end{array}$ & $\begin{array}{c}\boldsymbol{k}_{\mathbf{n r}} \\
\left(\mathbf{1 0} \mathbf{s}^{\mathbf{1}} \mathbf{)}\right.\end{array}$ \\
\hline $\mathbf{3}$ & & & & & & & & \\
\hline $\mathrm{MeOH}$ & $436 / 4.49$ & 3355 & 492 & 2611 & $0.40 \pm 0.06$ & $1.1 \pm 0.1$ & 0.37 & 0.54 \\
$\mathrm{CHCl}_{3}$ & $441 / 4.66$ & 2580 & 470 & 1399 & $0.44 \pm 0.07$ & $2.6 \pm 0.1$ & 0.17 & 0.22 \\
$\mathrm{PMMA}$ & $440 / 4.39$ & 2939 & 475 & 1675 & $0.81 \pm 0.12$ & $3.3 \pm 0.2$ & 0.24 & 0.06 \\
$\mathrm{PVC}$ & $446 / 4.56$ & 2918 & 482 & 1675 & $1.08 \pm 0.16$ & $4.0 \pm 0.2$ & 0.27 & - \\
$\mathrm{PS}$ & $438 / 4.41$ & 2555 & 468 & 1464 & $0.22 \pm 0.03$ & $2.5 \pm 0.1$ & 0.09 & 0.31 \\
\hline $\mathbf{4}$ & & & & & & & & \\
\hline $\mathrm{MeOH}$ & $431 / 4.48$ & 3402 & 503 & 3321 & $0.64 \pm 0.10$ & $1.8 \pm 0.1$ & 0.36 & 0.20 \\
$\mathrm{CHCl}$ & $433 / 4.61$ & 3811 & 492 & 2769 & $0.49 \pm 0.07$ & $1.8 \pm 0.1$ & 0.27 & 0.28 \\
$\mathrm{PMMA}$ & $432 / 4.35$ & 3894 & 504 & 3307 & $1.08 \pm 0.16$ & $3.6 \pm 0.2$ & 0.30 & - \\
$\mathrm{PVC}$ & $440 / 4.43$ & 3805 & 505 & 2925 & $1.10 \pm 0.17$ & $2.3 \pm 0.1$ & 0.48 & - \\
$\mathrm{PS}$ & $429 / 4.42$ & 4437 & 505 & 3508 & $0.25 \pm 0.04$ & $2.6 \pm 0.1$ & 0.10 & 0.29 \\
\hline $\mathbf{8}$ & & & & & & & & \\
\hline $\mathrm{MeOH}$ & $373 / 4.54$ & 5431 & 474 & 5713 & $0.007 \pm 0.001$ & & & \\
$\mathrm{CHCl}$ & $375 / 4.37$ & 5343 & 464 & 4973 & $0.011 \pm 0.002$ & $3.3 \pm 0.2$ & 0.003 & 0.30 \\
$\mathrm{PMMA}$ & $375 / 4.25$ & 4842 & 463 & 5068 & $0.30 \pm 0.05$ & $2.3 \pm 0.1$ & 0.13 & 0.30 \\
$\mathrm{PVC}$ & $379 / 4.38$ & 4547 & 466 & 4926 & $0.29 \pm 0.04$ & $1.9 \pm 0.1$ & 0.15 & 0.37 \\
$\mathrm{PS}$ & $375 / 4.14$ & 4876 & 465 & 5161 & $0.06 \pm 0.01$ & $0.7 \pm 0.04$ & 0.09 & 1.34 \\
\hline
\end{tabular}

Structure of the coumarins is given in Scheme 1. The media are as follows: methanol: $\mathrm{MeOH}$, Chloroform: $\mathrm{CHCl}_{3}$, poly(methyl metharylate): PMMA, poly(vinylchloride): PVC, polystyrene: PS; $\lambda_{\mathrm{A}}$ : maximum of absorption, $\log \varepsilon \cdot \log$ of decadic extinction coefficient, $\Delta v_{1 / 2}$ : half width of the longest wavelength absorption band $\lambda_{\mathrm{F}}$ : maximum of fluorescence, $\nu_{\mathrm{A}}-\nu_{\mathrm{F}}$ : Stoke's shift, $\Phi_{\mathrm{F}}$ : quantum yield of fluorescence based on anthracene, $\tau$. experimental life time, $k_{\mathrm{F}}$ : fluorescence rate constant from the $\mathrm{S}_{1}$ given as $k_{\mathrm{F}}=\Phi / \tau, k_{\mathrm{nr}}$ : radiationless rate constant from $\mathrm{S}_{1}$ given as $k_{\mathrm{nr}}=(1-\Phi) / \tau$. 
Table 3. Calculated spectral properties of 3,4 and 8, based on spectral data.

\begin{tabular}{|c|c|c|c|c|c|c|}
\hline $\begin{array}{l}\text { Comp./ } \\
\text { Medium }\end{array}$ & $\begin{array}{c}E_{\mathrm{S} 1} \\
\left(\mathrm{~kJ} \mathrm{~mol}^{-1}\right)\end{array}$ & $f$ & $\begin{array}{c}\tau_{0} \\
(\mathrm{~ns})\end{array}$ & $\begin{array}{c}\tau_{\text {F-calc }} \\
(\mathrm{ns})\end{array}$ & $\begin{array}{c}k_{\text {F-calc }} \\
\left(10^{9} \mathrm{~s}^{-1}\right)\end{array}$ & $\begin{array}{c}k_{\text {nr-calc }} \\
\left(10^{9} \mathrm{~s}^{-1}\right)\end{array}$ \\
\hline \multicolumn{7}{|l|}{3} \\
\hline $\mathrm{MeOH}$ & 258 & 0.33 & 8.5 & 3.4 & 0.12 & 0.18 \\
\hline $\mathrm{CHCl}_{3}$ & 263 & 0.34 & 8.6 & 3.8 & 0.12 & 0.15 \\
\hline PMMA & 261 & 0.31 & 9.3 & 7.5 & 0.11 & 0.03 \\
\hline PVC & 258 & 0.46 & 6.5 & 7.0 & 0.15 & - \\
\hline PS & 264 & 0.29 & 1.0 & 0.2 & 0.99 & 3.57 \\
\hline \multicolumn{7}{|l|}{4} \\
\hline $\mathrm{MeOH}$ & 256 & 0.34 & 8.3 & 5.3 & 0.12 & 0.07 \\
\hline $\mathrm{CHCl}_{3}$ & 259 & 0.45 & 6.2 & 3.0 & 0.16 & 0.17 \\
\hline PMMA & 267 & 0.38 & 7.4 & 8.0 & 0.14 & - \\
\hline PVC & 253 & 0.44 & 6.6 & 7.3 & 0.15 & - \\
\hline PS & 265 & 0.51 & 5.5 & 1.4 & 0.18 & 0.54 \\
\hline \multicolumn{7}{|l|}{8} \\
\hline $\mathrm{MeOH}$ & 282 & 0.61 & 3.4 & 0.02 & 0.29 & 45.0 \\
\hline $\mathrm{CHCl}_{3}$ & 284 & 0.36 & 5.9 & 0.06 & 0.17 & 15.0 \\
\hline PMMA & 285 & 0.25 & 8.5 & 2.51 & 0.12 & 0.3 \\
\hline PVC & 283 & 0.47 & 4.6 & 1.32 & 0.22 & 0.5 \\
\hline PS & 285 & 0.29 & 7.3 & 0.43 & 0.14 & 2.2 \\
\hline
\end{tabular}

$E_{\mathrm{S} 1}$ : energy of the singlet state $\mathrm{S}_{1}$, as $11.96 \times 10^{4} /\left[\left(\lambda_{\mathrm{A}}+\lambda_{\mathrm{F}}\right) / 2\right]$, i.e., from the intersection of the normalized fluorescence and absorption spectra, $f$ : oscillator strength given as $4.32 \times 10^{-9} \Delta v_{1 / 2} \varepsilon_{\max }$, $\tau_{0}$ : natural radiative lifetime of the excited singlet state, $\tau_{\text {F-calc }}$ : calculated fluorescence lifetime as $\tau_{\mathrm{F}-\text { calc }}=\tau_{0} \Phi_{\mathrm{F}}, k_{\mathrm{F} \text {-calc }}$ : calculated natural radiative decay rate constant for the excited singlet state as $\Phi_{\mathrm{F}} / \tau_{\mathrm{F}-\mathrm{cal}}, k_{\mathrm{nr}-\mathrm{cal}}:$ calculated nonradiative decay rate constant for the excited singlet state as $\left(1-\Phi_{\mathrm{F}}\right) / \tau_{\mathrm{F}-\text { calc }}$.

The absorption spectrum of non-substituted coumarin aldehyde 1, in both the solution and polymer matrices, exhibits two bands without vibrational structure in the UV region at approximately 305 and $350 \mathrm{~nm}$. The absorption maxima $\left(\lambda_{\mathrm{A}}\right)$ of both bands are shifted to longer wavelengths with increasing solvent polarity. The bathochromic shift of absorption maxima implies that the electronic transitions corresponding to these bands are $\pi-\pi^{*}$ transitions. Both $\pi-\pi^{*}$ transitions are typical for basic coumarin skeletons and are related to the charge transfer from the benzenic cycle to the pyranone moiety [63]. These transitions are associated to an excitation from the HOMO (the highest occupied molecular orbital) and the HOMO-1 orbital, respectively, to the LUMO (the lowest unoccupied molecular orbital). Due to the presence of a relatively strong electron-withdrawing formyl group (CHO) at position 3, the absorption maxima of 1 are shifted more batochromically $(\sim 30-40 \mathrm{~nm})$ in comparison with unsubstituted coumarin. Introduction of the methyl substituent to position 7 in the coumarin ring of 1 leads to bathochromic shift of both bands, decreasing the distance between the two absorption bands and changing the ratio of their intensities (Figure 2, compound 5). The methoxy substitution of hydrogen in position 7 of the coumarin aldehyde 1 promotes an overlapping of these absorption bands to one intense bathochromically shifted absorption band with small long-wavelength shoulder (Figure 2, compound 7), while the introduction of a dimethylamino group into position 7 of 1 leads to a most 
intense, bathochromically shifted, single broad structure-less absorption band (Figure 2, compound 3). This behaviour is explained by the increasing intramolecular charge transfer (ICT) character of molecules 5,7 and $\mathbf{3}$ (in this order, as depicted in Scheme 1), in comparison with the parent carbaldehyde 1. Because the HOMO-1 to LUMO electronic transition of $\mathbf{1}$ is (similarly as in the case of unsubstituted coumarin) related to a larger redistribution of charges, the increasing ICT character of compound 5, 7 and $\mathbf{3}$ is associated with the decreasing distance and consecutive overlapping of the two absorption bands, increasing intensity (transition dipole moments) and decreasing energy in the corresponding electronic transitions.

Scheme 1. Proposed intramolecular charge transfer (ICT) character of the studied molecules.<smiles>Cc1ccc2cc(C=O)c(=O)oc2c1</smiles>

:D

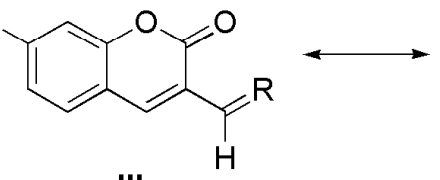

III<smiles></smiles><smiles>[R]/C=c1\cc2c(oc1=O)=CC(=[OH+])C=C2</smiles>
IV

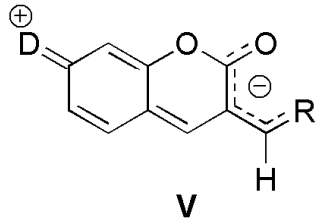

$$
\mathrm{D}=-\mathrm{OCH}_{3},-\mathrm{N}\left(\mathrm{CH}_{3}\right)_{2}
$$

$\mathrm{R}=-\mathrm{O},-\mathrm{N}-\mathrm{NH}-\mathrm{CO}-\mathrm{NH}-\mathrm{Ph}$

The exceptions from the uniform behavior are absorption spectra of aldehydes $\mathbf{1}$ and $\mathbf{5}$ in methanol (Supporting Figure 1; Table 1). As shown in Figure S1, these spectra are very different in comparison to spectra of these molecules in chloroform and in all studied polymer matrices (the new absorption band with the highest intensity appears at approximately $280 \mathrm{~nm}$ and the ratio of the intensities of two absorption bands above $300 \mathrm{~nm}$ alters). They look like the absorption spectra of unsubstituted or 7-methyl-substituted coumarin (with shoulders at approximately $350 \mathrm{~nm}$ ). This indicates decreased conjugation between the formyl group in position 3 of the coumarin ring and the rest of the molecule. ${ }^{1} \mathrm{H}-\mathrm{NMR}$ spectra revealed the presence of signal from methoxy protons due to formation of a dimethyl acetal, explaining the changes in the shape of the absorption spectra of $\mathbf{1}$ and $\mathbf{5}$.

The main absorption bands in UV-VIS spectra of phenylsemicarbazides $\mathbf{2 , 4 , 6 , 8}$ lay also in the near UV region. In comparison to aldehydes $1,5,7$, the shape of the absorption spectra of phenylsemicarbazides $\mathbf{2 , 6 , 8}$ changes to one band which is slightly red-shifted to $360-380 \mathrm{~nm}$. We assume that this behaviour is associated with increasing conjugation length of the chromophoric system due to overlapping of $\pi$-orbitals of phenylsemicarbazide group with $\pi$-orbitals of coumarin moiety. The increasing conjugation length is apparent from the downfield shift of the signal for urea moiety -NH- protons in ${ }^{1} \mathrm{H}-\mathrm{NMR}$ spectra of semicarbazides 4,6 and $\mathbf{8}$ in comparison to semicarbazide 2 (Supporting Figure 2). As shown in Supporting Figure 2, the introduction of methyl group to position position 7 of the coumarin skeleton leads to remarkable shift of the ${ }^{1} \mathrm{H}-\mathrm{NMR}$ signal for both $-\mathrm{NH}-$ protons of phenylsemicarbazide moiety (the cross-conjugation effect). Condensation of the parent carbaldehydes $\mathbf{1}$ and $\mathbf{5}$ with 4-phenylsemicarbazide leads to an increase in the extinction coefficient of semicarbazides $\mathbf{2}$ and $\mathbf{6}$, whereas it only has a weak effect on the extinction of compounds $\mathbf{4}$ and $\mathbf{8}$. 
As shown in Figure 2, the substitution with dimethylamino group in position 7 of the coumarin aldehyde 1, and/or non-substituted semicarbazide 2, shifts the absorption approximately 80 to $100 \mathrm{~nm}$ in both the solution and the polymer matrix, and it also exhibits a higher extinction coefficient (Table 2, compounds 3 and 4). The methyl and methoxy substitution in position 7 effects a smaller red shift in the longest wavelength band of approximately $10-20 \mathrm{~nm}$. As stated above, this effect is assigned to the increased extent of ICT character in coumarins $\mathbf{3}$ and $\mathbf{4}$, involving coumarins with dimethylamino group in position 7 of the coumarin ring. This is due to the stabilization of resonance structures IV and V depicted in Scheme 1. The hypsochromic shift of $\lambda_{\mathrm{A}}$ of 4 , compared to that in the parent aldehyde $\mathbf{3}$, in both solution and polymer matrices could thus be a consequence of the weaker electron-withdrawing character of the $-\mathrm{C}=\mathrm{N}-\mathrm{R}$ substituent, compared to the carbonyl group in parent aldehyde 3.

\subsection{Fluorescence Spectra}

The spectral data based on absorption for parent derivatives $\mathbf{1}$ and $\mathbf{2}$, methyl substituted derivates 5 and $\mathbf{6}$ and the methoxy substituted 7 are summarized in Table 1. These compounds exhibit zero or weak fluorescence with a quantum yield below 0.001 . Substitution in position 7 , however, results in a slight increase in fluorescence intensity in both the solution and polymer matrices for these derivatives. The quantum yield value of fluorescence for 5, 6, 7 is approximately 0.001 . The florescence spectral data for $\mathbf{1}, \mathbf{2}, \mathbf{5}, \mathbf{6}$, and 7 exhibits large error, especially for those in the polymer matrices and therefore these are not included in Table 1.

Introduction of the electron donating group with a $+\mathrm{M}$ effect to position 7 , as witnessed in the dimethylamino and/or methoxy groups, caused a dramatic increase in the fluorescence intensity, demonstrated in the spectral data for $\mathbf{3}$ and $\mathbf{4}$, and also partly for $\mathbf{8}$ (Table 2). This effect is generally well documented in the literature [1,5], together with an additional increase in fluorescence intensity after introduction of electron withdrawing group to position 3 of such 7-substituted coumarins [62]. The fluorescence illustrated in Figure 3 consists of a single broad band without vibrational structure. However, for $\mathbf{8}$ alone, a shoulder is witnessed at the short wavelength edge of the fluorescence band in both the solution and the polymer matrices. A shoulder is also observed for 4 in $\mathrm{CHCl}_{3}$, at the long wavelength edge of the fluorescence band (Figure 3A).

The Stoke's shift, indicating the extent of the red shift of the fluorescence maximum $\left(\lambda_{\mathrm{F}}\right)$ compared to the absorption maxima $\left(\lambda_{\mathrm{A}}\right)$, is the lowest for $\mathbf{3}$, falling within the range of 1,500 to $2,500 \mathrm{~cm}^{-1}$. Meanwhile, the Stoke's shift is larger for 4, at approximately $3,000 \mathrm{~cm}^{-1}$, and the largest shift is for 8 at approximately $5,000 \mathrm{~cm}^{-1}$. This indicates more significant structural changes between the ground and excited states of 8 compared with those for $\mathbf{4}$ and $\mathbf{3}$. The comparison of $\lambda_{\mathrm{A}}$ and $\lambda_{\mathrm{F}}$ values for phenylsemicarbazides $\mathbf{4}$ and $\mathbf{8}$ (differ only in the character of the substituent in position 7 in the coumarin ring) indicates that the difference in the Stoke's shift for molecules $\mathbf{4}$ and $\mathbf{8}$ results more from the difference in $\lambda_{\mathrm{A}}$ than from the difference in $\lambda_{\mathrm{F}}$. We assume that the reason for the larger Stoke's shift of $\mathbf{8}$ in comparison with $\mathbf{4}$ is therefore connected with the difference in the ICT character of the ground state of these molecules. The charge redistribution in the ground state of molecule $\mathbf{8}$ exists somewhere between resonance structures III and IV (Scheme 1), and it is most likely closer to resonance structure IV when this is compared with the charge redistribution in the ground state of 4 . 
Figure 3. (A) Fluorescence spectra of $\mathbf{3}, \mathbf{4}$ and $\mathbf{8}$ in $\mathrm{CHCl}_{3}$ at $10^{-5} \mathrm{~mol} \cdot \mathrm{dm}^{-3}$. (B) Fluorescence spectra of 3, 4 and $\mathbf{8}$ in PMMA at $0.002 \mathrm{~mol} \mathrm{~kg}^{-1}$.
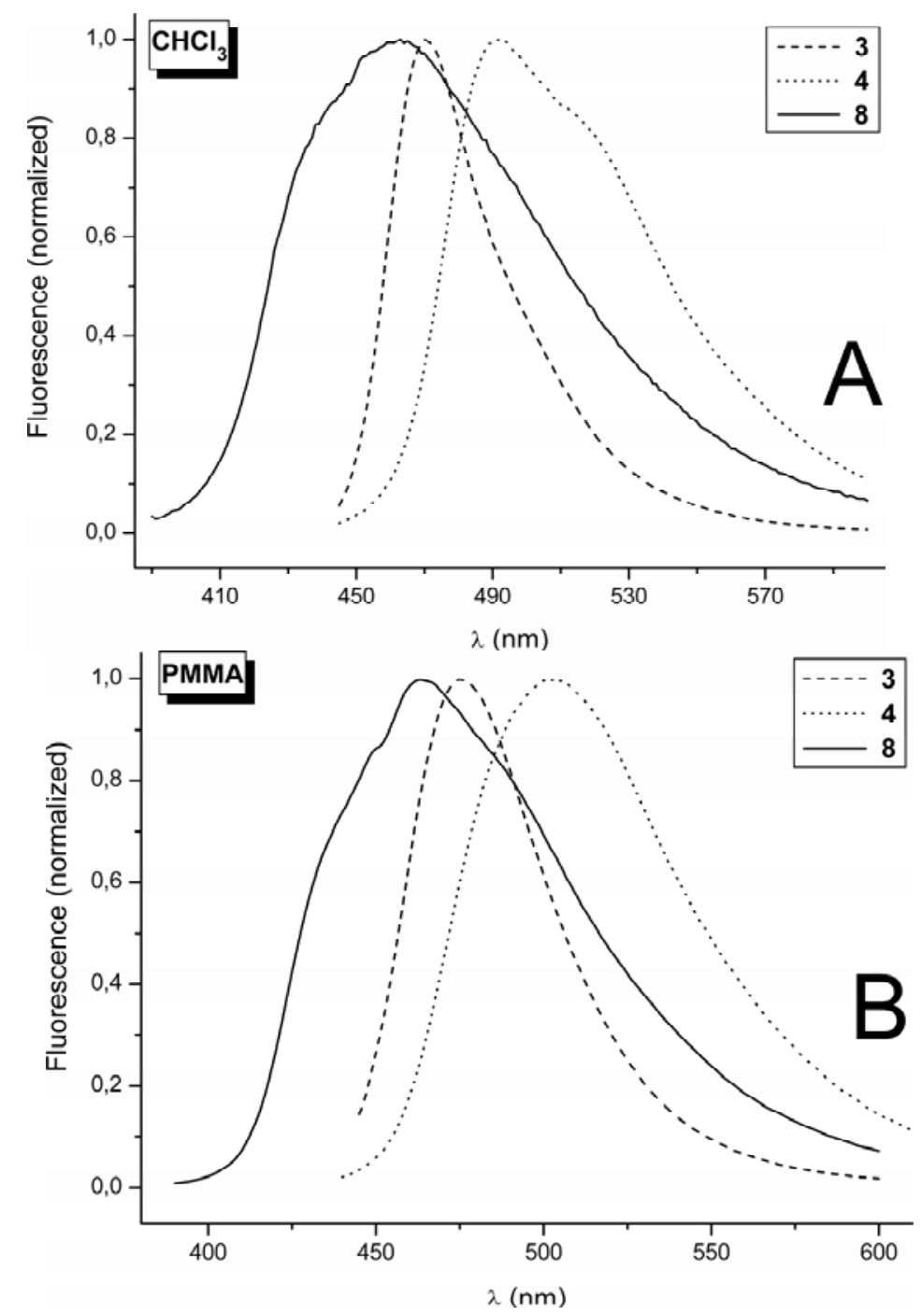

The intense fluorescence of 3 and 4 exhibits maxima in the 470-505 nm range depending on the medium. Although the determination of quantum yields of fluorescence $(\Phi)$ is charged with a large error (of approximately \pm 10 up to 20\%), the value of $\Phi$ is high, reaching 1 for 3 in PVC and for 4 in PMMA and PVC. Previously, high fluorescence was observed for push pull type of di-substituted coumarin with thiosemicarbazide in polar dimethylsulfoxide (DMSO), with the $k_{\mathrm{F}}$ higher than $k_{\mathrm{nr}}$, classifying this dye as laser one in the given medium [62]. We observed similar effect for dyes 3 and 4 (Table 2) doped in the polar polymer matrices, where besides decreased rotation of substituent at position 3 some stiffening of the structure of disubstituted coumarin due to dipolar interaction between dopant and matrix may occur. The dyes $\mathbf{3}$ and $\mathbf{4}$ might have some potential as laser dyes. The methoxy derivative $\mathbf{8}$ exhibits lower intensity fluorescence than the $\mathbf{3}$ and $\mathbf{4}$ derivatives with 7-dimethylamino substitution.

Comparison of the quantum yields of fluorescence $(\Phi)$ of derivatives $\mathbf{3}, \mathbf{4}$ and $\mathbf{8}$ (Table 2) in solution and in polymer matrices reveals that quantum yield values are higher in the polymer matrices than in solution. This effect has already been observed for 3-phenylcoumarin [39]. The decrease in fluorescence is due to the increased rotation of the group in position 3 in the medium of lower 
micro-viscosity that increases the rate of non-radiative deactivation of the $\mathrm{S}_{1}$ state. Comparing $\Phi$ within polymer matrices, approximately equal fluorescence quantum-yield values were observed for PMMA and PVC, while PS experienced the lowest values.

The experimentally determined fluorescence lifetimes $(\tau)$ are in the range of $0.7-4$ ns. Combination of quantum yield $\Phi$ and experimentally determined lifetime $\tau$ yields the radiation rate constant $k_{\mathrm{F}}$. This data can be compared with radiation rate constants $\left(k_{\mathrm{F}-\mathrm{calc}}\right)$, which are calculated using absorption data. This radiation rate constant is expressed as $1 / \tau_{0}$, where $\tau_{0}$ is the natural radiation lifetime. Comparison of $k_{\mathrm{F}}$ (Table 2, column 9) and $k_{\mathrm{F}-\mathrm{cal}}$ (Table 3, column 6) shows that $k_{\mathrm{F}}$ are slightly higher than $k_{\mathrm{F}-\mathrm{cal}}$ for 3, 4 and 8. Both $k_{\mathrm{F}}$ and $k_{\mathrm{F}-\mathrm{cal}}$ are in the range of $1-10 \times 10^{8} \mathrm{~s}^{-1}$. Some discrepancies are noted, however, for fluorophor $\mathbf{3}$ in the PS matrix. The quantum yields of all three chromophores $\mathbf{3}, \mathbf{4}$ and $\mathbf{8}$ in the PS polymer matrix are lower compared to those in PMMA and PVC. At the same time, $k_{\mathrm{F}}$ is one order lower than the $k_{\mathrm{F}-\mathrm{calc}}$ for $\mathbf{3}$ in PS. This data clearly indicates that the PS matrix is less inert than PMMA and PVC, and that it exerts a quenching effect on the studied push-pull coumarins. The PMMA and PVC matrices appear to have the required polarity and micro-viscosity to suppress non-radiative processes, so that the quantum yield of fluorescence approaches unity in these matrices. We assume that specific $\pi-\pi$ interactions between coumarin moiety of the studied compounds and benzene ring of the PS matrix contribute to non-radiative decay of the excited states of the studied coumarins. Futher studies should determine whether any additional factors play a role in these mechanisms.

\section{Experimental}

\subsection{General}

Melting points (uncorrected) were measured on a Kofler hot stage. ${ }^{1} \mathrm{H}$ - and ${ }^{13} \mathrm{C}-\mathrm{NMR}$ spectra were recorded on Varian Mercury Plus 300 spectrometer (operating at $300 \mathrm{MHz}$ for ${ }^{1} \mathrm{H}$ and $75 \mathrm{MHz}$ for ${ }^{13} \mathrm{C}$ ) in $\mathrm{DMSO}_{-} \mathrm{d}_{6}$ or $\mathrm{CDCl}_{3}$ with TMS as internal standard. Chemical shifts $(\delta)$ are reported in ppm downfield of TMS and coupling constants $(J)$ are expressed in Hertz $(\mathrm{Hz})$. All the chemicals and solvents were purchased from major chemical suppliers (Merck, Darmstadt, Germany; Acros Organics, Geel, Belgium; Sigma-Aldrich, St. Louis, MO, USA) in highest grade purity, and all solvents were dried by standard methods and distilled prior to use. Elemental analyses were performed on a Carlo Erba Strumentacione 1106 apparatus. 7-(Dimethylamino)-2-oxo-2H-chromene3-carbaldehyde (Mp 204-205 ${ }^{\circ} \mathrm{C}$, lit. [60] $205{ }^{\circ} \mathrm{C}$ ) was prepared by 3-step reaction, according to literature [60]. 7-H (Mp 133-134 ${ }^{\circ} \mathrm{C}$, lit. [64] $\left.134{ }^{\circ} \mathrm{C}\right)$, 7-methyl $\left(\mathrm{Mp} 174-176{ }^{\circ} \mathrm{C}\right.$, lit. [64] $\left.176{ }^{\circ} \mathrm{C}\right)$ and 7-methoxy (Mp 235-237 ${ }^{\circ} \mathrm{C}$, lit. [64] $238{ }^{\circ} \mathrm{C}$ ) carbaldehydes were prepared by a modified procedure $[64,65]$. The structure of prepared aldehydes was proved from their ${ }^{1} \mathrm{H}-\mathrm{NMR}$ spectra.

\subsection{Synthesis of Coumarin Derivatives}

The general synthetic route is shown in Scheme 2. 
Scheme 2. Synthesis of substituted coumarins.<smiles>[R]c1ccc(C=O)c(O)c1</smiles><smiles></smiles>

$\mathrm{R}=-\mathrm{H},-\mathrm{CH}_{3},-\mathrm{OCH}_{3},-\mathrm{NMe}_{2}$

\subsection{Reaction of Aldehydes with Phenylsemicarbazide}

General Procedure

A solution of phenylsemicarbazide $(0.7 \mathrm{mmol} ; 105 \mathrm{mg})$ in hot absolute ethanol $(3 \mathrm{~mL})$ was added to 2-oxo- $2 \mathrm{H}$-chromene-3-carbaldehyde $(0.7 \mathrm{mmol})$ in hot absolute EtOH $(5 \mathrm{~mL})$. The reaction mixture was refluxed for $15 \mathrm{~min}$, and the desired products was precipitated, filtered and washed with cold ethanol, and then dried and re-crystallized from ethanol. The crude products were obtained in $98-99 \%$ yields.

(E)-1-[(2-Oxo-2H-chromen-3-yl)methylidene]-4-phenylsemicarbazide (2): Obtained from 1 (122 mg) in 97\% yield (208 mg), Mp 216-219 ${ }^{\circ} \mathrm{C},{ }^{1} \mathrm{H}-\mathrm{NMR}\left(\mathrm{CDCl}_{3}\right): \delta 7.03-7.07(1 \mathrm{H}, \mathrm{m}, \mathrm{Ar}-\mathrm{H}), 7.30-7.35$ $(2 \mathrm{H}, m, \mathrm{Ar}-\mathrm{H}), 7.39-7.47$ (2H, $m, \mathrm{Ar}-\mathrm{H}), 7.62-7.66(3 \mathrm{H}, m, \mathrm{Ar}-\mathrm{H}), 7.77(1 \mathrm{H}, d d, J=7.8 \mathrm{~Hz}, 1.5 \mathrm{~Hz}$, $\mathrm{H}-8), 8.05(1 \mathrm{H}, s, \mathrm{H}-4), 8.86(1 \mathrm{H}, s, \mathrm{NH}), 9.01(1 \mathrm{H}, s, \mathrm{NH}), 11.10(1 \mathrm{H}, s, \mathrm{HC}=\mathrm{N}) ;{ }^{13} \mathrm{C}-\mathrm{NMR}\left(\mathrm{CDCl}_{3}\right)$ : $\delta 116.29,119.19,120.13,121.299,122.78,125.04,128.51,128.92,132.18,133.69,137.24,138.82$, 152.75, 153.09, 159.88; Anal. Calcd for $\mathrm{C}_{17} \mathrm{H}_{13} \mathrm{~N}_{3} \mathrm{O}_{3}$ (307.3): C, 66.44; H, 4.26; N, 13.68. Found: C, $66.42 ; \mathrm{H}, 4.33 ; \mathrm{N} 13.65$.

(E)-1-\{[(7-Dimethylamino)2-oxo-2H-chromen-3-yl]methylidene $\}$-4-phenylsemicarbazide (4): Obtained from $3(152 \mathrm{mg})$ in 98\% yield $(240 \mathrm{mg}),{ }^{1} \mathrm{H}-\mathrm{NMR}$ (DMSO): $\delta 3.07\left(6 \mathrm{H}, s,-\mathrm{N}\left(\mathrm{CH}_{3}\right)_{2}\right), 6.61(1 \mathrm{H}, d$, $J=2.1 \mathrm{~Hz}, \mathrm{Ar}-\mathrm{H}), 6.81(1 \mathrm{H}, d d, J=9 \mathrm{~Hz}, 2.1 \mathrm{~Hz}, \mathrm{Ar}-\mathrm{H}), 7.00-7.05(1 \mathrm{H}, m, \mathrm{Ar}-\mathrm{H}), 7.28-7.33(2 \mathrm{H}, m$, Ar-H), $7.53(1 \mathrm{H}, d, J=9 \mathrm{~Hz}, \mathrm{Ar}-\mathrm{H}), 7.66(2 \mathrm{H}, d d, J=8.7 \mathrm{~Hz}, 1.2 \mathrm{~Hz}, \mathrm{Ar}-\mathrm{H}), 7.99(1 \mathrm{H}, s, \mathrm{H}-4), 8.68$ $(1 \mathrm{H}, s, \mathrm{NH}), 8.89(1 \mathrm{H}, s, \mathrm{NH}), 10.85(1 \mathrm{H}, s, \mathrm{HC}=\mathrm{N}) ;{ }^{13} \mathrm{C}-\mathrm{NMR}(\mathrm{DMSO}): \delta 40.35,97.17,108.49$, 110.06, 113.45, 119.89, 122.54, 128.47, 129.85, 135.01, 138.47, 129.00, 152.85, 153.24, 155.81, 160.74; Anal. Calcd for $\mathrm{C}_{19} \mathrm{H}_{18} \mathrm{~N}_{4} \mathrm{O}_{3}$ (350.4): C, 65.13; H, 5.18; N, 15.99. Found: C, 65.12; H, 5.14; N 15.82 .

(E)-1-[(7-Methyl-2-oxo-2H-chromen-3-yl)methylidene]-4-phenylsemicarbazide (6): Obtained from 5 $(132 \mathrm{mg})$ in $98 \%$ yield $(220 \mathrm{mg}), \mathrm{Mp} 217-218{ }^{\circ} \mathrm{C}{ }^{1} \mathrm{H}-\mathrm{NMR}\left(\mathrm{CDCl}_{3}\right): \delta 2.49\left(3 \mathrm{H}, \mathrm{s}, \mathrm{CH}_{3}\right), 7.09-7.19$ (3H, $m, \mathrm{Ar}-\mathrm{H}), 7.33-7.39$ (2H, $m, \mathrm{Ar}-\mathrm{H}), 7.50-7.58(3 \mathrm{H}, m, \mathrm{Ar}-\mathrm{H}), 7.95(1 \mathrm{H}, s, \mathrm{H}-4), 8.04(1 \mathrm{H}, s, \mathrm{NH})$, 8.23(1H, $s, \mathrm{HC}=\mathrm{N}), 8.29(1 \mathrm{H}, s, \mathrm{NH}) ;{ }^{13} \mathrm{C}-\mathrm{NMR}\left(\mathrm{CDCl}_{3}\right) \delta 22.01,116.56,117.04,119.76,119.82$, 123.83, 126.33, 128.40, 129.08, 135.07, 137.53, 137.78, 144.33, 152.20, 153.93, 160.35; Anal. Calcd for $\mathrm{C}_{18} \mathrm{H}_{15} \mathrm{~N}_{3} \mathrm{O}_{3}$ (321.3): C, 67.28; H, 4.71; N, 13.08. Found: C, 67.43; H, 4.72; N 13.07. 
(E)-1-[(7-Methoxy-2-oxo-2H-chromen-3-yl)methylidene]-4-phenylsemicarbazide (8): Obtained from 7 $(143 \mathrm{mg})$ in $97 \%$ yield $(229 \mathrm{mg}), \mathrm{Mp} 218-220{ }^{\circ} \mathrm{C}{ }^{1} \mathrm{H}-\mathrm{NMR}\left(\mathrm{CDCl}_{3}\right): \delta 3.91\left(3 \mathrm{H}, \mathrm{s},-\mathrm{OCH}_{3}\right), 6.86(1 \mathrm{H}$, $d, J=2.4 \mathrm{~Hz}, \mathrm{Ar}-\mathrm{H}), 6.92(1 \mathrm{H}, d d, J=8.7 \mathrm{~Hz}, 2.4 \mathrm{~Hz}, \mathrm{Ar}-\mathrm{H}), 7.08-7.14(1 \mathrm{H}, m, \mathrm{Ar}-\mathrm{H}), 7.33-7.39$ (2H, $m$, Ar-H), $7.51-7.60$ (3H, $m$, Ar-H), $7.92(1 \mathrm{H}, s, \mathrm{H}-4), 8.03(1 \mathrm{H}, s, \mathrm{NH}), 8.09(1 \mathrm{H}, s, \mathrm{NH}), 8.22$ $(1 \mathrm{H}, s, \mathrm{HC}=\mathrm{N}) ;{ }^{13} \mathrm{C}-\mathrm{NMR}\left(\mathrm{CDCl}_{3}\right): \delta 55.96,100.79,103.98,112.61,113.60,117.37,119.75,123.79$, 129.07, 129.79, 135.23, 137.57, 137.99, 152.13, 155.86, 163.71; Anal. Calcd for $\mathrm{C}_{18} \mathrm{H}_{15} \mathrm{~N}_{3} \mathrm{O}_{4}(337.3)$ : C, 64.09; H, 4.48; N, 12.46. Found: C, 64.08; H, 4.51; N 12.29.

\subsection{Spectral Measurements}

Anthracene was zonally refined (Lachema n.e., Brno, CR, USA). The methanol and chloroform were UV spectroscopy grade (Merck, Darmstadt, Germany). Polymer films doped with coumarins were prepared by casting from solution. Films of polystyrene (PS; Kratsen, Kaucuk s.e., Kralupy, ČR, $\left.\mathrm{M}_{\mathrm{w}}=1.1 \times 10^{5} \mathrm{D}\right)$ and poly(methylmethacrylate) (PMMA; Diacon, ICI, England, $\left.\mathrm{M}_{\mathrm{v}}=1.01 \times 10^{5} \mathrm{D}\right)$ were prepared by casting $1 \mathrm{~mL}$ chloroform solution of polymer $(5 \mathrm{~g} / 100 \mathrm{~mL})$ containing the appropriate amount of probe onto a $28 \times 35 \mathrm{~mm}$ glass plate. The solvent was evaporated slowly. Films of poly(vinylchloride) (PVC) (Neralite 628, Spolana Neratovice, s.e., С̆R, $\mathrm{M}_{\mathrm{w}}=1.11 \times 10^{5} \mathrm{D}$ ) were prepared similarly by casting from tetrahydrofuran solution. All three polymers were additive free. The rest of solvents were additionally not removed from the polymer.

UV-VIS absorption spectra were recorded with an UV 1650PC spectrometer (Shimadzu, Japan), and fluorescence spectra with either a RF-5301 (Shimadzu, Japan) or a FSP 920 (Edinburgh Instruments, UK) spectrofluorimeters. The Origin 6.1 (Microcal) was used for data plotting. Fluorescence of solution was measured in a $1 \mathrm{~cm}$ cuvette in the right-angle arrangement, and the quantum yields were determined relative to anthracene in chloroform and methanol. Polymer film fluorescence was taken in front face arrangement on the solid sample holder.

The fluorescent quantum yield of disubstituted coumarins was determined in solution and in polymer films using anthracene as the standard in the given medium, taking the quantum yield of anthracene in cyclohexane equal to 0.25 [66]. The anthracene fluorescence quantum yields in the different media were determined by the comparison with the anthracene fluorescence in cyclohexane. These values are 0.22 in acetonitrile, 0.20 in methanol, and 0.11 in chloroform. In polymer matrices, the quantum yields were assumed to be 0.20 in PMMA, 0.16 in PS and 0.11 in PVC. The quantum yields in the solutions and films were corrected to different absorptions at the excitation wavelength [67], and fluorescence spectra were taken using excitation at the longest wavelength absorption-band maxima.

The fluorescence lifetime measurements were performed on a LIF 200 (Lasertechnik Ltd., Berlin, Germany), which operates as a stroboscope. The excitation source was a nitrogen laser emitting at $337 \mathrm{~nm}$ and the emission was selected by cut-off filter. The output signal of Box Car Integrator was digitized and transferred to the PC using a home-made programme. The fluorescence decay curves were evaluated by the simple phase plane method [68] using J. Snyder's programme [69]. The standard deviation $G^{1 / 2}=\Sigma\left(\left(I_{\text {exp }}-I_{\text {calc }}\right)^{2} / n\right)^{1 / 2}$, where $I_{\text {exp }}$ and $I_{\text {calc }}$ define the intensities of experimental and calculated emission, respectively, was employed to establish if the decay was mono-exponential. It was assumed that the decay curve satisfies the mono-exponential when $\mathrm{G}^{1 / 2}$ was below $5 \%$. The fluorescence decay of the studied compounds was reasonably fitted with monoexponential function. 
The error was less than 5\%. The steady state and time-resolved fluorescence measurements were performed in aerated solutions. All measurements on polymer films were performed in the air.

\subsection{Relationships in the Calculation of Spectral Properties}

$$
\begin{aligned}
& E_{S 1}=\frac{11.96 \times 10^{4}}{\left(\frac{\lambda_{A}+\lambda_{F}}{2}\right)} \quad \text { i.e., from the intersection of the normalized fluorescence and absorption spectra } \\
& f=4.32 \times 10^{-9} \Delta v_{1 / 2} \varepsilon_{\max } / n, \quad \text { for the molecule in solvent, } \\
& \text { where } n=\text { the refractive index of the solvent } \\
& f=4.32 \times 10^{-9} \Delta v_{1 / 2} \varepsilon_{\max }, \quad \text { for molecule in polymer matrix } \\
& \tau_{0}=\frac{1.5}{\widetilde{v}_{\max }^{2} f} \\
& \left(v_{A}-v_{F}\right)=\left(\frac{1}{\lambda_{A}}-\frac{1}{\lambda_{F}}\right) \cdot 10^{7} \\
& k_{\mathrm{F}}=\Phi_{\mathrm{F}} / \tau \quad k_{\mathrm{F} \text {-calc }}=1 / \tau_{0} \\
& k_{\mathrm{nr}}=\left(1-\Phi_{\mathrm{F}}\right) / \tau \quad k_{\mathrm{nr}-\mathrm{calc}}=\left(1-\Phi_{\mathrm{F}}\right) / \tau_{\mathrm{F}-\mathrm{calc}} \\
& \tau_{\mathrm{F}-\mathrm{calc}}=\tau_{0} \Phi_{\mathrm{F}} \\
& \Phi_{F(X)}=\Phi_{F(S)}\left(\frac{A_{S}}{A_{X}}\right)\left(\frac{F_{X}}{F_{S}}\right) \text {, } \\
& s=\text { the standard (anthracene) } \\
& A=\text { the value of absorbance at the excitation wavelength } \\
& F=\text { the plane under the emission curve }
\end{aligned}
$$

\section{Conclusions}

Substituted coumarins (2-oxo- $2 \mathrm{H}$-chromenes) with various electron donating ability in position 7 , such as $\mathrm{H}, \mathrm{CH}_{3}, \mathrm{OCH}_{3}, \mathrm{~N}\left(\mathrm{CH}_{3}\right)_{2}$ and substituted in position 3 by $\mathrm{CHO}$ or $-\mathrm{CH}=\mathrm{NNHCONHPh}$, were investigated. Introduction of the electron-donating group to position 7 of the coumarin ring in the non-substituted coumarin aldehyde leads to a noticeable change in absorption spectrum shape and a substantial red-shift of the absorption maximum. This behaviour is explained by the increasing intramolecular charge transfer (ICT) character of substituted aldehydes. Replacement of the formyl group in position 3 of the coumarin ring by a $-\mathrm{CH}=\mathrm{NNHCONHPh}$ group also markedly influences the shape of the absorption spectrum, and this change is substantial in non-substituted and methyl-substituted coumarins. We assume that increasing conjugation length of the chromophoric system (due to overlapping of $\pi$-orbitals of phenylsemicarbazide group with $\pi$-orbitals of coumarin moiety) is responsible for this effect. However, only a small change was recorded in the 7-dimethylamino substituted coumarin. 
The fluorescence is almost negligible for derivatives not substituted in position 7 (compounds 1 and 2), and also for derivatives with weak or medium electro-donating character of substituent in position 7 (compounds 5, 6 and 7). Introduction of a strong electron donating group with $+\mathrm{M}$ effect, such as the dimethylamino group, to position 7 of the coumarin ring provides a significant increase in fluorescence intensity. A noticeable fluorescence was observed for the methoxy derivative 8, and it was very intense in the 7-dimethylamino coumarins 3 and 4 . Surprisingly, the different charge redistribution in the ground state of molecules $\mathbf{3 , 4}$ and $\mathbf{8}$ is mainly responsible for the different values of the Stoke's shifts of these molecules. The quantum yield of both 7-dimethylamino derivatives approaches 1 in PMMA and PVC polymer matrices. The finding that chromophores $\mathbf{3}$ and $\mathbf{4}$ exhibit quantum yields approaching 1 in the polymer matrices is explained by the medium-suppressed rotation of the side substituent at position 3 in the given media. We assume that stiffening of the dopant due to higher micro-viscosity and dipole-dipole interaction between dopant and matrix occurs in the polar matrices of PMMA and PVC. The dyes 3 and 4 might be classified as laser ones in the given medium. The fluorescence lifetime is in the range $0.5-4 \mathrm{~ns}$. Based on experimental results, the fluorescence radiation rate constant is approximately $5 \times 10^{8} \mathrm{~s}^{-1}$, and this value is in accordance with those determined from the absorption spectra.

\section{Supplementary Materials}

Supplementary materials can be accessed at: http://www.mdpi.com/1420-3049/17/3/3259/s1.

\section{Acknowledgments}

This work was supported by the Slovak Grant Agency for Science (grant no. 1/1126/11).

\section{References and Notes}

1. Lakowicz J.R. Principles of Fluorescence Spectroscopy; Kluwer Academic/Plenum Publishers: New York, NY, USA, 1999; Chapter 3, p. 280.

2. Valeur, B. Molecular Fluorescence: Principles and Aplications; Wiley-Verlag Chemie GmbH.: Weinheim, Germany, 2001; Chapter 3, p. 79.

3. Prasanna de Silva, A.; Gunaratante, H.Q.N.; Gunnlaugsson, Th.; Huxley, A.J.M.; Mc Coy, C.P.; Rademacher, J.T.; Rice, T.E. Signaling recognition events with fluorescent sensors and switches. Chem. Rev. 1997, 97, 1515-1566.

4. Prasanna de Silva, A.; Vance, T.P.; West, M.E.S.; Wright, G.D. Bright molecules with sense, logic, numeracy and utility. Org. Biomol. Chem. 2008, 6, 2468-2481.

5. Acceta, R.; Corradini, R.; Marcelli, R. Enantioselective sensing by luminescence. Top. Curr. Chem. 2011, 300, 175-216.

6. Jones, G., II; Jackson, W.R.; Choi, C.Y.; Bergman, W.R. Solvent effect on emission yield and lifetime for coumarin laser dyes. Requirement for rotatory decay mechanism. J. Phys. Chem. 1985, 89, 294-300.

7. Horng, M.L.; Gardeski, J.A.; Papazyan, A.; Maroncelli, M. Subpicosecond measurement of polar salvation dynamics: Coumarin 153 revisited. J. Phys. Chem. 1995, 99, 17311-17337. 
8. Arbeloa, T.L.; Arbeloa, F.L.; Arbeloa, I.L. Influence of fluorinated group on the photophysics of 7-aminocoumarins. J. Lumin. 1996, 68, 149-155.

9. Du, D.M.; Wang, Y.M.; Meng, J.B. Micro-environmental effects on the photochemical and photophysical processes of long chain coumarin esters. Chem. J. Chin. Univ.-Chin. 1998, 19, 1611-1613.

10. Raju, B.B.; Costa, S.M.B. Photophysical properties of 7-diethylaminocoumarin dyes in dioxanewater mixtures: Hydrogen bonding, dielectric enrichment and polarity effects. Phys. Chem. Chem. Phys. 1999, 1, 3539-3547.

11. Ramalingam, A.; Sivaram, B.M.; Palamisamy, P.K.; Masilamani, V. Photophysics of TICT states of 7-diethylamino-4-methyl coumarin dye by energy transfer techniques. Spectrochim. Acta Part A-Mol. Biomolec. Spect. 2000, 56, 1205-1210.

12. Morimoto, A.; Yatsuhashi, T.; Shimada, T.; Biczok, L.; Tryk, D.A.; Inoue, H. Radiationless deactivation of an intramolecular charge transfer excited state through hydrogen bonding: Effect of molecular structure and hard-soft anionic character in the excited state. J. Phys. Chem. A 2001, $105,10488-10496$.

13. Morlet-Savary, F.; Ley, C.; Jacques, P.; Fouasier, J.P. Photophysics of a bridged 7-diethylamino4-methylcoumarin C102: Studying the hydrogen bonding effect by time resolved stimulated emission. J. Phys. Chem. A 2001, 105, 11026-11033.

14. Satpati, A.K.; Senthilkumar, S.; Kumbhakar, M.; Nath, S.; Maity, D.K.; Pal, H. Investigations of the solvent polarity effect on the photophysical properties of coumarin-7 dye. Photochem. Photobiol. 2005, 81, 270-278.

15. Satpati, A.K.; Kumbhakar, M.; Maity, D.K.; Pal, H. Photophysical investigations of the solvent polarity effect on properties of coumarin-6 dye. Chem. Phys. Lett. 2005, 407, 114-118.

16. Mandal, P.K.; Paul, A.; Samanta, A. Fluorescence studies of environmentally benign solvents: Solvation dynamics of coumarin 102 in [BMIM][BF4]. Res. Chem. Intermed. 2005, 31, 575-583.

17. Raikar, U.S.; Renuka, C.G.; Nadaf, Y.F.; Mulimani, B.G.; Karguppikar, A.M. Rotational diffusion and solvatochromic correlation of coumarin 6 laser dye. J. Fluoresc. 2006, 16, 847-854.

18. Raikar, U.S.; Renuka, C.G.; Nadaf, Y.F.; Mulimani, B.G.; Karguppikar, A.M.; Soudagar, M.K. Solvent effects on the absorption and fluorescence spectra of coumarins 6 and 7 molecules: Determination of ground state and excited state dipole moment. Spectrochim. Acta A 2006, 65, 673-677.

19. Tablet, C.; Hildebrand, M. Quenching of the fluorescence of carboxy-5,6-benzocoumarin by aromatic amines. J. Photochem. Photobiol. A Chem. 2007, 189, 73-79.

20. Wang, T.; Zhao, Y.; Shi, M.; Wu, F. The synthesis of novel coumarin dyes and the study of their photoreaction properties. Dyes Pigments 2007, 75, 104-110.

21. Ammar, H.; Abid, S.; Fery-Forgues, S. Synthesis and spectroscopic study of new biscoumarin dyes based on 7-(4-methylcoumarinyl) diesters. Dyes Pigments 2008, 78, 1-7.

22. Winnik, F.M.; Regismond, S.T.A. Fluorescence methods in the study of the interactions of surfactants with polymers. Colloids Surf. A Physicochem. Eng. Asp. 1996, 118, 1-36.

23. De Paula, R.; De Hora, A.E.; Machado De Miranda, J.A. 3-Benzoxazol-2-yl-7-(N,Ndiethylamino)/chromen-2-one as a fluorescence probe for investigation of micellar microenvironments. J. Photochem. Photobiol. A Chem. 2004, 165, 109-114. 
24. Das, K.; Jain, B.; Gupta, P.K. Photophysics of coumarin 500 and coumarin 151 in AOT revers micelles. Chem. Phys. Lett. 2005, 410, 160-164.

25. Tamoto, Y.; Segawa, H.; Shirota, H. Solvation dynamics in aqueous anionic and cationic micelle solutions: Sodium alkyl sulfate and alkyltrimethylamonium bromide. Langmuir 2005, 21, 3757-3764.

26. Scypinski, S.; Drake, J.M. Photophysics of coumarin inclusion complexes with inverted comples formation. J. Phys. Chem. 1985, 89, 2432-2435.

27. Chakraborty, A.; Seth, D.; Chakrabarty, D.; Sarkar, N. Photoinduced intermolecular electron transfer from aniline to 7 -amino coumarin dyes in the surface of $\beta$-cyclodextrin. Spectrochim. Acta Part A 2006, 64, 801-808.

28. Li, D.; Zhang, J.; Anpo, M.; Xue, M.; Liu, Y. Photophysical properties of coumarin-6 molecules incorporated within MCM-48. Materials Lett. 2005, 59, 2120-2123.

29. Guan, H.; Zhu, L.; Zhou, H.; Tang, H. Rapid probing of photoactivity on titania based self-cleaning materials using 7-hydroxycoumarin fluorescent probe. Anal. Chim. Acta 2008, 608, 73-78.

30. Takahashi, Y.; Shimada, R.; Maeda, A.; Kojima, K.; Uchida, K. Photophysics of coumarin 4 doped-amorphous silica glasses prepared by sol-gel method. J. Lumin. 1996, 68, 187-192.

31. Stathatos, E.; Lianos, P.; Lavrencic-Stangar, U.; Orel, B. Study of laser action of coumarine-153 incorporated in sol-gel made silica/poly(propylene oxide) nanocomposite gels. Chem. Phys. Lett. 2001, 345, 381-385.

32. Takahashi, Y.; Maeda, A.; Kojima, K. Optical pH sensing characteristics in dye-doped sol-gel coating film base on the energy transfer. Jpn. J. Appl. Phys. 1 2003, 42, 4369-4377.

33. Yamaguchi, A.; Amino, Y.; Shima, K.; Suzuki, S.; Yamashita, T.; Teramae, N. Local environments of coumarin dyes within mesostructured silica-surfactant nanocomposites. J. Phys. Chem. B 2006, 110, 3910-3916.

34. Sabatini, C.A.; Pereira, R.V.; Gehlen, M.H. Fluorescence modulation of acridin and coumarine dyes by silver nanoparticles. J. Fluoresc. 2007, 17, 377-382.

35. Soutar, I. The application of Luminescence Technique in Polymer Science. Polym. Int. 1991, 26, 35-49.

36. Morawetz, H. On the versatility of fluorescence technique in polymer research. J. Polym. Sci. A Polym. Chem. 1999, 37, 1725-1735.

37. Sarker, A.M.; Kaneko, Y.; Neckers, D.C. Photochemistry and photophysics of novel photoinitiators: $\quad N, N, N$-Tributyl-N-(4-methylene-7-methoxycoumarin)ammonium borates. J. Photochem. Photobiol. 1998, 117, 67-74.

38. Oh, J.K.; Wu, J.; Winnik, M.A.; Croun, G.P.; Rademacher, J.; Farwaha, R. Emulsion copolymerization of vinyl acetate and butylacetate in the presence of fluorescent dyes. J. Polym. Sci. Part A Polym. Chem. 2002, 40, 1594-1604.

39. Kaholek, M.; Hrdlovič, P. Spectral properties of coumarin derivatives substituted at position 3. Effect of polymer matrix. J. Photochem. Photobiol. A Chem. 1997, 108, 283-288.

40. Kaholek, M.; Hrdlovič, P. Characteristics of excited states of 3-substituted coumarin derivatives and transfer of electronic energy to N-oxyl radicals. J. Photochem. Photobiol. A Chem. 1999, 127, $45-55$. 
41. Kaholek, M.; Hrdlovič, P.; Bartos, J. Singlet probes based on coumarin derivatives substituted at position 3; spectral properties in solution and polymer matrices. Polymer 2000, 41, 991-1001.

42. Jones, G.; Jimenez, J.A.C. Azole-linked coumarin dyes as fluorescence probes of domain-forming polymers. J. Photochem. Photbiol. B Biol. 2001, 65, 5-12.

43. Kim, C.; Trajkovskaja, A.; Wallace, J.U.; Chen, S.H. New insight into photoalignment of liquid crystals on coumarin containing polymer films. Macromolecules 2006, 39, 3817-3823.

44. Ley, J.G.E.; Tirumalasetty, P.P. Release chracteristics of polymethylmethcrytate nanospheres containing coumarin 6. J. Microencapsul. 2003, 20, 653-659.

45. Mansour, A.F.; Killa, H.M.A.; El-Wanees, S.A.; El-Sayed, M.Y. Laser dyes doped with with (ST-co-MMA) as fluorescent solar collectors and their field performance. Polym. Testing 2005, 24, 519-525.

46. Felorzabihi, N.; Haley, J.C.; Bardajee, G.; Winnik, M.A. Systematic study of the fluorescence decay of amino-coumarins dyes in polymer matrices. J. Polym. Sci. B Polym. Phys. 2007, 45, $2333-2343$.

47. Fu, Q.; Cheng, L.; Zhang, Y.; Shi, W. Preparation and reversible photocrosslinking/photo-cleavage of 4-methylcoumarin functionalized hyperbranched polyester. Polymer 2008, 49, 4981-4988.

48. Bayer, M.; Steger, D.; Fischer, K. The Luminescence of lignign-containing pulps-A comparison with fluorescence of model compounds in several media. J. Photochem. Photobiol. A Chem. 1993, 76, 217-224.

49. Fischer, K.; Spange, S.; Fischer, S.; Bellmann, C.; Adams, J. Probing the surface polarity of native cellulose using genuine solvatochromic dyes. Cellulose 2002, 9, 31-40.

50. Nad, S.; Pal, H. Electron transfer from diphenyl and triphenyl amines to excited coumarin dyes. J. Photochem. Photobiol. A Chem. 2000, 134, 9-15.

51. Nad, S.; Pal, H. Electron transfer from aromatic amines to excited coumarin dyes.Fluorescence qenching and picosecond transient absorption studies. J. Phys. Chem. 2000, 104, 673-680.

52. Coenjarts, C.; Garcia, O.; Llauger, L.; Vinette, A.L.; Scaiano, J.C. Mapping photogenerated radicals in thin polymer films: Fluorescence imaging using a prefluorescent radical probe. J. Am. Chem. Soc. 2003, 125, 620-621.

53. Scaiano, J.C.; Aliaga, C.; Chretien, M.N.; Frenette, M.; Focsaneanu, K.S.; Mikelson, L. Fluorescence sensor application as detector for DNA damage, free radical formation, and in microlithography. Pure Appl. Chem. 2005, 77, 1009-1018.

54. Danko, M.; Szabo, E.; Hrdlovič, P. Synthesis and spectral characterization of fluorescence dyes based on coumarin fluorophore and hindered amine stabilizer in solution and polymer matrices. Dyes Pigments 2011, 90, 129-138.

55. Viriota, M.L.; Carre, M.C.; Geoffroy-Chapotot, C.; Brembilla, A.; Muller, S.; Stoltz, J.-F. Molecular rotors as fluorescent probes for biological studies. Clin. Hemorheol. Microcirc. 1998, 19, 151-160.

56. Keskin, S.S.; Aslan, N.; Bayrakceken, F. Optical properties and chemical behavior of laser dye coumarin-500and the influence of atmospheric corona discharge. Spectrochem. Acta A Biomol. Spectros. 2009, 72, 254-259.

57. Christie, R.M.; Morgan, K.M.; Islam, M.S. Molecular design and synthesis of arylsulfonated coumarin fluorescent dyes and their application to textile. Dyes Pigments 2008, 76, 741-747. 
58. Leray, I.; Habib-Jiwan, J.-L.; Branger, C.; Soumillion, J.-Ph.; Valeur, B. Ion responsive fluorescent compounds VI. Ccoumarin 153 linked to rigid crowns for improvement of selectivity. J. Photochem. Photobiol. A Chem. 2000, 135, 163-169.

59. Nakazono, M.; Saita, K.; Kurihara, Ch.; Nanbu, S.; Zaitsu, K. Intramolecular energy transfer in š-amino-N-(7-methoxy-4'-methylcoumaryl)phthalimide. J. Photochem.Photobiol. A Chem. 2009, 208, 21-26.

60. Flašík, R.; Stankovičová, H.; Gáplovský, A.; Donovalová, J. Synthesis and study of novel derivatives potentially utilizable as memory media. Molecules 2009, 14, 4838-4848.

61. Hrdlovič, P.; Donovalová, J.; Stankovičová, H.; Gaplovský, A. Influence of polarity of solvents on spectral properties of Bichromophoric Coumarins. Molecules 2010, 15, 8915-8932.

62. Bangar, R.B.; Varandajaran, T.S. Substituent and solvent effects on the twisted intramolecular charge transfer of three new 7-(diethylamino)coumarin-3-aldehyde derivatives. J. Phys. Chem. 1994, 98, 8903-8905.

63. Preat, J.; Jacquemin, D.; Wathelet, V.; André, J.-M.; Perpète, E.A. TD-DFT Investigation of the UV Spectra of Pyranone Derivatives. J. Phys. Chem. A 2006, 110, 8144-8150.

64. René, L.; Lefebvre, A.; Auzou, G. An Easy Conversion of $2 H$-chromenes into Coumarins. An Entry to 3-Formyl Coumarins. Synthesis 1986, 7, 567-569.

65. Auzov, G.; René, L. Obtention de dialkylamino-2 cyano-3 2H-chromènes. J. Heterocycl. Chem. 1986, 23, 955-956.

66. Birks, J.B. Photophysics of Aromatic Molecules; Willey-Interscience: New York, NY, USA, 1968; Chapter 4, pp. 121-127.

67. Kawski, A.; Kubicki, A.; Kuklinski, B.; Gryczynski, I. Unusual absorption and fluorescence properties of 1,6-diphenyl-1,3,5-hexatriene in poly(vinyl alcohol) film. J. Photochem. Photobiol. A: Chem. 1993, 71, 161.

68. Demas, J.N.; Adamson, A.W. Evaluation of photoluminescence lifetimes. J. Phys. Chem. 1971, $57,2463$.

69. Demas, J.N. Excited State Lifetime Measurements; Academic Press: New York, NY, USA, 1973; Appendix 4, p. 245.

Sample Availability: Samples of compounds 1-8 are available from the authors.

(C) 2012 by the authors; licensee MDPI, Basel, Switzerland. This article is an open access article distributed under the terms and conditions of the Creative Commons Attribution license (http://creativecommons.org/licenses/by/3.0/). 